\title{
Aspectos clínicos e patológicos da paratuberculose em bovinos no Rio Grande do Sul ${ }^{1}$
}

\author{
David Driemeier ${ }^{2}$, Claudio Estevão Farias Cruz ${ }^{3}$, Marcos José Pereira Gomes ${ }^{4}$, Luís \\ Gustavo Corbellini ${ }^{5}$, Alexandre Paulino Loretti ${ }^{6}$ e Edson Moleta Colodel ${ }^{7}$
}

\begin{abstract}
Driemeier D., Cruz C.E.F., Gomes M.J.P., Corbellini L.G., Loretti A.P. \& Colodel E.M. 1999. [Clinical and pathological aspects of bovine paratuberculosis in Rio Grande do Sul, southern Brazil.] Aspectos clínicos e patológicos da paratuberculose em bovinos no Rio Grande do Sul. Pesquisa Veterinária Brasileira 19(3/4):109-115. Setor de Patologia Veterinária, Depto Patologia Clínica Veterinária, Faculdade de Veterinária, Universidade Federal do Rio Grande do Sul, Av. Bento Gonçalves 9090, Cx. Postal 15094, Porto Alegre, RS 91540-000, Brazil.

The clinical and pathological aspects of bovine paratuberculosis in a dairy herd in the county of Capela de Santana, Rio Grande do Sul, southern Brazil, are described. Clinical signs in eight cows out of 345 cattle included chronic diarrhea refractory to treatment, progressive emaciation and decreased milk production. Necropsy findings included severe and diffuse thickening of the mucosa of the small intestine with exaggerated reticular pattern, reflected in the serosal surface, similar to cerebral gyri. Intestinal loops were filled with whitish watery contents. The lymphatic vessels of the intestinal serosa and of the mesentery were thickened and tortuous. The mesenteric lymph nodes were enlarged and, on cut surface, there were oozing of milky fluid. Plaques of mineralization were evident in the intima of larger arteries, in the endocardium of the heart valves and in the ruminal serosa. There was also edema of the abomasal folds and atrophy of the caudate lobe of the liver. The main histopathological findings were granulomatous enteritis, lymphadenitis and lymphangitis. The inflammatory infiltrate was composed of macrophages, epithelioid cells and Langhans' giant cells containing large numbers of acid-fast bacilli. Vascular lesions included degeneration, calcification and collagen proliferation of the intima and media of larger arteries. Other microscopic lesions included calcification of the ruminal serosa, diffuse hepatocellular atrophy and multifocal granulomatous hepatitis. Mycobacterium paratuberculosis was cultured in Herrold's medium enriched with mycobactin from all the eight samples of intestinal scrapings submitted to bacteriological examination.
\end{abstract}

INDEX TERMS: Paratuberculosis, Mycobacterium paratuberculosis, Johne's disease, ruminants, pathology.

\footnotetext{
${ }^{1}$ Aceito para publicação em 5 de novembro de 1998.

${ }^{2}$ Setor de Patologia Veterinária, Depto Patologia Clínica Veterinária, Faculdade de Veterinária, Universidade Federal do Rio Grande do Sul (UFRGS), Av. Bento Gonçalves 9090, Cx. Postal 15094, Porto Alegre, RS 91540-000; bolsista do CNPq (301076/93-6).

${ }^{3}$ Médico-veterinário autônomo, Porto Alegre, RS.

${ }^{4}$ Setor de Bacteriologia Veterinária, Depto Patologia Clínica Veterinária, Faculdade de Veterinária, UFRGS.

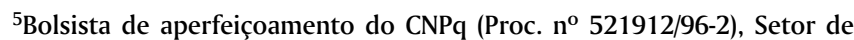
Patologia Veterinária, Depto Patologia Clínica Veterinária, Faculdade de Veterinária, UFRGS.

${ }^{6}$ Setor de Patologia Veterinária, Depto Patologia Clínica Veterinária, Faculdade de Veterinária, UFRGS.

${ }^{7}$ Professor da Disciplina de Patologia Geral e Comparada, Depto Clínica Médica Veterinária, Faculdade de Agronomia e Medicina Veterinária, Fundação Universidade Federal de Mato Grosso, Av. Fernando Corrêa Pinto s/n $\mathbf{n}^{\mathbf{0}}$, Bairro Coxipó, Cuiabá, MT 78060-900.
}

RESUMO.- Descrevem-se os achados clínicos e patológicos da paratuberculose em uma criação intensiva de bovinos de leite no município de Capela de Santana, RS. Sinais clínicos foram observados em oito de um total de 345 bovinos e consistiam em diarréia crônica refratária ao tratamento, emagrecimento progressivo e queda da produção de leite. As principais lesões macroscópicas, observadas nos oito animais eutanasiados e necropsiados, incluíam intestino delgado com acentuado espessamento da parede e superfície mucosa de aspecto reticulado, semelhante às circunvoluções cerebrais, lesão essa perceptível através da serosa. A luz intestinal estava preenchida por conteúdo fluido e de aspecto leitoso. Os vasos linfáticos do mesentério mostravam-se mais evidentes, sendo que alguns tinham aspecto varicoso. Os linfonodos mesentéricos estavam aumentados de volume e, ao corte, fluía grande quantidade de líquido leitoso. Focos de 
mineralização foram observados na íntima das artérias, nas válvulas cardíacas e na serosa do rúmen. Havia também edema das dobras do abomaso e do mesentério e atrofia do lobo caudado do fígado. As principais lesões microscópicas incluíam enterite, linfadenite e linfangite granulomatosas que se caracterizavam por infiltrado inflamatório composto por macrófagos, células epitelióides e células gigantes de Langhans que continham grande quantidade de bacilos álcool-ácido resistentes. As lesões vasculares consistiam em degeneração e mineralização das túnicas íntima e média das artérias de grande calibre associadas à proliferação de colágeno. Havia calcificação da serosa do rúmen, atrofia hepatocelular difusa e hepatite granulomatosa multifocal. Mycobacterium paratuberculosis foi cultivado em meio de Herrold enriquecido com micobactina a partir de raspados do intestino em todas as oito amostras enviadas para exame bacteriológico.

TERMOS DE INDEXAÇÃO: Paratuberculose, Mycobacterium paratuberculosis, doença de Johne, ruminantes, patologia.

\section{INTRODUÇÃO}

A paratuberculose ou doença de Johne é uma enterite granulomatosa, crônica, infecciosa e que afeta ruminantes domésticos e silvestres (Chiodini et al. 1984, Kreeger 1991), cujo agente etiológico é Mycobacterium paratuberculosis. Trata-se de uma enfermidade de distribuição mundial. Nos Estados Unidos, um estudo sobre o isolamento do agente etiológico em linfonodos mesentéricos, revelou uma prevalência de $2,9 \%$ em bovinos de leite e $0,8 \%$ em bovinos de corte (Merkal et al. 1987). Na África do Sul, há relatos da enfermidade em animais importados (Huchzermeyer et al. 1994).

A transmissão de $M$. paratuberculosis pode ocorrer por via intra-uterina, no período pós-natal através do colostro e, principalmente, pela fezes de animais contaminados (Sweeney 1996). Bovinos que desenvolvem a doença clínica, em geral são aqueles infectados nas primeiras semanas de vida. A doença clínica manifesta-se geralmente em animais com idade superior a 2 anos (Radostits et al. 1994, Sweeney 1996). Fatores estressantes, tais como parto e má nutrição, podem desencadear o aparecimento dos sinais clínicos (Kreeger 1991, Whitlock \& Buergelt 1996). A doença é mais frequente em bovinos confinados em função da maior contaminação do ambiente pelas fezes (Radostits et al. 1994).

A paratuberculose é responsável por perdas econômicas que ocorrem pela redução na produtividade, maior susceptibilidade a outras doenças, aumento dos custos sanitários e maior taxa de descarte precoce (Hutchinson 1996). Estima-se que 5\% dos bovinos com a doença clínica representam 50\% dos animais infectados em um rebanho (Radostits et al. 1994). Diversos testes imunológicos auxiliam na identificação de portadores assintomáticos, porém não são definitivos no que se refere à prevalência da doença (Stehman 1990).

As principais lesões macroscópicas ocorrem no intestino delgado e caracterizam-se por acentuado espessamento da mucosa, que assume aspecto rugoso e aumento de tamanho dos linfonodos mesentéricos. Os principais achados histopatológicos consistem em enterite, linfangite e linfadenite granu- lomatosas associados à presença de bacilos álcool-ácido resistentes em macrófagos (Chiodini et al. 1984, Kreeger 1991). Alterações vasculares degenerativas nas artérias e no endocárdio, referidas por alguns autores como arteriosclerose, também são descritas e provavelmente são causadas por distúrbios metabólicos associados à infecção (Alibasoglu et al. 1962, Buergelt et al. 1978).

M. paratuberculosis é incriminado, por alguns autores, como agente envolvido em uma ileocolite granulomatosa de humanos denominada doença de Crohn. No entanto, a participação de $M$. paratuberculosis na etiologia desta enfermidade não está completamente esclarecida e requer maiores investigações (Chiodini \& Rossiter 1996).

No Brasil, um dos principais aspectos da epidemiologia da paratuberculose diz respeito à importação de bovinos infectados, de forma semelhante ao que ocorre na África do Sul. A doença já foi diagnosticada em bovinos importados e naqueles nascidos no país, filhos de pais importados. Os relatos são esporádicos e impedem uma estimativa das perdas econômicas em rebanhos infectados. Há seis descrições da doença na Região Sudeste, nos Estados do Rio de Janeiro (Dupont 1915, Dacorso Filho et al. 1960, Santos \& Silva 1956, Silva \& Pizelli 1961, Silva 1968) e Minas Gerais (Nakajima et al. 1991), e duas na Região Sul, nos Estados de Santa Catarina (Portugal et al. 1979) e do Rio Grande do Sul (Ramos et al. 1986). A enfermidade foi reproduzida experimentalmente em ovinos e caprinos (Silva 1968, Poester \& Ramos 1994).

O presente estudo objetiva descrever o quadro clínicopatológico de casos de paratuberculose em bovinos em um rebanho leiteiro no Estado do Rio Grande do Sul.

\section{MATERIAL E MÉTODOS}

Dados epidemiológicos e sinais clínicos da doença nos bovinos foram obtidos junto ao proprietário e através de visitas ao estabelecimento. Foram eutanasiados e necropsiados oito bovinos e coletados fragmentos de intestinos delgado (duodeno, jejuno, íleo incluindo a válvula íleocecal) e grosso (ceco, cólon e reto), mesentério, linfonodos mesentéricos, retrofaríngeos, mediastínicos e supra-mamários, fígado, baço, vesícula biliar, pâncreas, rúmen, abomaso, rim, pulmão, encéfalo, coração, aorta, carótida, tireóide e paratireóide, útero e glândula mamária. Estas amostras foram fixadas em formol tamponado a $10 \%$, incluídas em parafina, cortadas em micrótomo rotativo a $5 \mu \mathrm{m}$ e coradas com hematoxilina-eosina. Cortes dos intestinos, linfonodos, mesentério, fígado e pele foram corados pelas técnicas de Ziehl-Neelsen e Perls.

Foram coletados fragmentos da válvula íleo-cecal de todos os bovinos necropsiados e enviados para exame bacteriológico. A partir desse material, também foram feitos raspados da mucosa intestinal. Os esfregaços foram fixados em metanol e corados pelo método de Ziehl-Neelsen. Amostras da mucosa do intestino foram congeladas a $-20^{\circ} \mathrm{C}$ e posteriormente submetidas a isolamento em meio de cultivo específico de Herrold enriquecido com micobactina (Stabel 1997). A identificação do microrganismo foi realizada de acordo com os critérios descritos por Collins (1996).

\section{RESULTADOS}

Histórico

Os primeiros casos da doença foram observados no mês de dezembro de 1997, em um estabelecimento localizado no município de Capela de Santana, RS. O rebanho era formado por 345 bovinos da raça holandesa que incluíam vacas em 
ordenha e vacas secas (todas importadas da Argentina), bezerras de até 6 meses de idade (filhas destas vacas nascidas no Brasil) e um touro (adquirido de outro tambo próximo da propriedade e que nasceu no Brasil). A idade das vacas com lesões de paratuberculose era de 3 a 5 anos e o número de partos variou de 1 a 3 (Quadro 1). Do total, 220 vacas, importadas da Argentina, estavam em ordenha e eram mantidas em free-stall. Em agosto de 1997, todos os animais (345) foram submetidos à tuberculinização através da prova caudal simples com tuberculina mamífera. Cinquenta e cinco bovinos foram reagentes ao teste, sendo encaminhados ao abate sanitário. Destes, 38 animais apresentavam lesões generalizadas de tuberculose e 17 mostravam lesões localizadas.

\section{Sinais clínicos}

Os sinais clínicos consistiam em diarréia esverdeada, intermitente, emagrecimento progressivo (Fig. 1), queda da produção de leite, desidratação e pêlos arrepiados e sem brilho. Duas vacas (bovinos 2 e 3 ) apresentavam eczemas crostosos ao redor do ânus. Todos os bovinos afetados foram retirados da ordenha, em função da baixa produção de leite. Estes animais foram medicados com diferentes antimicrobianos, porém a enfermidade mostrou-se refratária aos tratamentos. O quadro clínico era crônico. Os primei-

\begin{tabular}{cccc}
\multicolumn{5}{c}{$\begin{array}{c}\text { Quadro } \\
\text { necropsiados }\end{array}$} & $\begin{array}{c}\text { Bovinos com paratuberculose } \\
\text { Bovino } \\
\text { no. }\end{array}$ & $\begin{array}{c}\text { Idade } \\
\text { (anos) }\end{array}$ & $\begin{array}{c}\mathrm{N}^{\circ} \text { de } \\
\text { partos }\end{array}$ & $\begin{array}{c}\text { Período de } \\
\text { gestação (meses) }\end{array}$ \\
\hline 1 & 4 & 1 & - a \\
2 & 4 & 3 & - \\
3 & 5 & 2 & - \\
4 & 4 & 2 & - \\
5 & 4 & 1 & 4 \\
6 & 4 & 1 & - \\
7 & 4 & 1 & - \\
8 & 3 & 1 & \\
\hline ava não-gestante & &
\end{tabular}

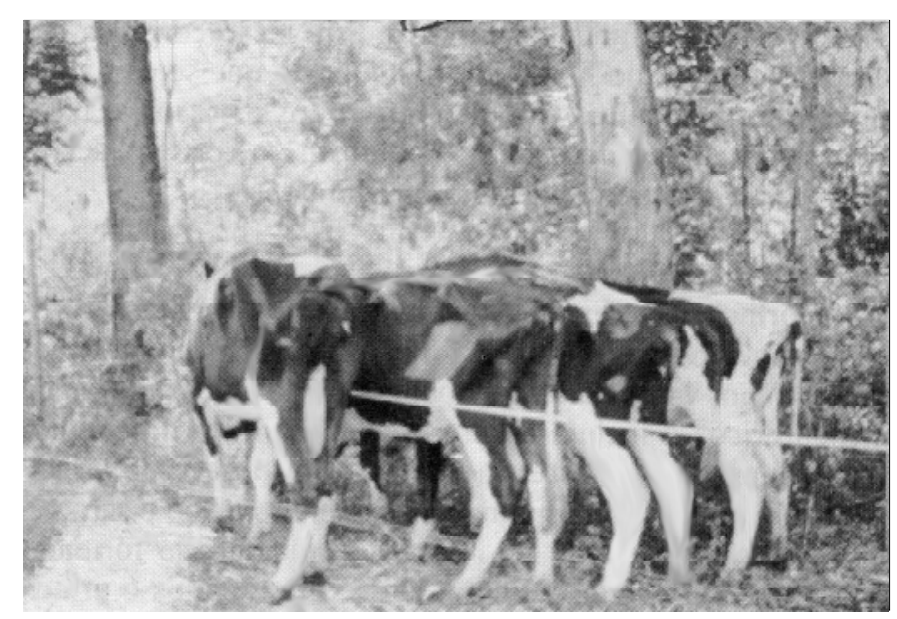

Fig. 1. Vacas com paratuberculose em mau estado geral e com sinais de diarréia (bovinos 1 a 4 ).
Quadro 2. Principais achados de necropsia em bovinos com paratuberculose no Rio Grande do Sul

\begin{tabular}{ccccc}
\hline $\begin{array}{c}\text { Bovino } \\
\text { no. }\end{array}$ & $\begin{array}{c}\text { Espessamento } \\
\text { da mucosa } \\
\text { do intestino } \\
\text { delgado }\end{array}$ & $\begin{array}{c}\text { Vasos linfáticos } \\
\text { do mesentério } \\
\text { mais evidentes }\end{array}$ & $\begin{array}{c}\text { Mineralização } \\
\text { das artérias }\end{array}$ & $\begin{array}{c}\text { Mineralização } \\
\text { da serosa } \\
\text { do rúmen }\end{array}$ \\
\hline 1 & ++ a & + & +++ & +++ \\
2 & ++ & ++ & ++ & - \\
3 & +++ & +++ & ++ & - \\
4 & ++ & ++ & +++ & +++ \\
5 & +++ & +++ & +++ & ++ \\
6 & +++ & +++ & ++ & - \\
7 & +++ & ++ & + & - \\
8 & + & & + &
\end{tabular}

ros sinais clínicos foram observados até 6 meses antes da eutanásia dos bovinos acometidos e apareciam geralmente após o parto.

\section{Achados de necropsia}

Os oito bovinos necropsiados estavam em mau estado nutricional. Havia atrofia serosa dos depósitos de gordura que era mais evidente no epicárdio. Em todos os casos, a parede do intestino delgado estava espessada e a lesão variava em intensidade (Quadro 2). Esta lesão era mais acentuada nos dois terços finais do intestino delgado. A serosa das alças intestinais mostrava-se irregular, com leves ondulações e apresentava aspecto reticulado. Em dois animais (bovinos 5 e 7), esta lesão era mais grave de modo que a serosa intestinal assumia a forma de mosaico. Secções transversais foram feitas em diversos segmentos dos intestinos. No íleo, verificou-se que, naqueles casos em que a lesão era mais acentuada, não havia colabamento completo das paredes do intestino de modo que este mantinha seu lúmen, mesmo sem conteúdo. A mucosa estava nitidamente espessada, quando comparada às demais camadas do intestino. A superfície mucosa mostrava-se irregular, de aspecto reticulado semelhante às circunvoluções cerebrais, com dobras transversais bem evidentes (Fig. 2). Havia conteúdo fluido e de aspecto leitoso acumulado entre as dobras da mucosa intestinal afetada. $\mathrm{A}$ inserção do mesentério às alças intestinais apresentava áreas com edema gelatinoso e translúcido. Os vasos linfáticos da serosa intestinal e do mesentério estavam mais evidentes e tinham aspecto varicoso (Fig. 3). Alguns linfáticos estavam preenchidos por líquido transparente. Outros eram esbranquiçados, firmes e de aspecto nodoso. Os linfonodos mesentéricos estavam aumentados de volume em até três vezes o seu tamanho normal. Ao corte, fluía grande quantidade de líquido leitoso. A região cortical destes linfonodos era esbranquiçada e a região medular enegrecida. Em alguns casos, a cortical tinha coloração marrom-clara bem evidente. Nos linfonodos mesentéricos de um animal (bovino 1), observou-se, ao corte, a presença de pequenos nódulos de aspecto caseoso, de aproximadamente $0,5 \mathrm{~cm}$ de diâmetro. Em todos os animais necropsiados, havia edema do mesentério, de intensidade leve a moderada, e em dois casos 

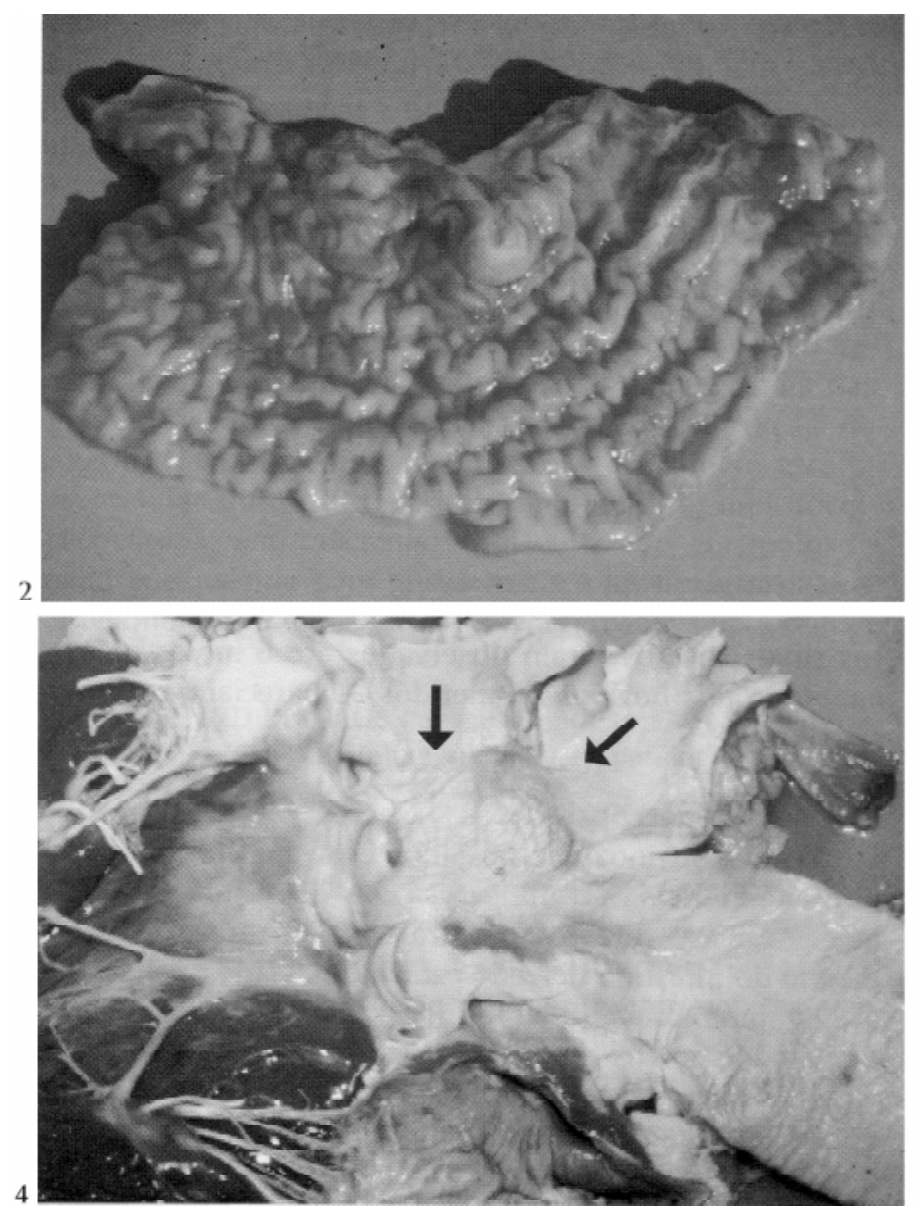

Fig. 2. Íleo com mucosa espessada, de aspecto corrugado semelhante às circunvoluções cerebrais, com dobras transversais bem evidentes (bovino 2).

Fig. 4. Mineralização da parede e das válvulas semilunares da aorta; presença de placas esbranquiçadas, opacas, irregulares na luz da aorta (bovino 6).

(bovinos 7 e 8), edema leve a moderado das dobras da mucosa do abomaso.

Mineralização da parede de artérias foi observada em todos os bovinos necropsiados. As lesões caracterizavam-se pela presença de placas esbranquiçadas, opacas, irregulares e que se salientavam na superfície interna dos grandes vasos. A intensidade das lesões era variável. Em dois animais (bovinos 7 e 8), estas alterações eram discretas e restringiam-se à base da aorta, à válvula mitral e às semilunares da aorta (Fig. 4). As lesões eram de intensidade moderada em três casos (bovinos 2, 3 e 6) e consistiam em calcificação de extensas áreas da superfície da aorta abdominal. Em três animais (bovinos 1, 4 e 5), havia acentuada mineralização da aorta abdominal, da artéria mesentérica e dos seus principais ramos e da artéria carótida.

Calcificação da serosa do rúmen foi observada em três bovinos (Fig. 5). As lesões eram esbranquiçadas, estriadas ou granulares e, nas porções centrais, havia a formação de placas sólidas. Estas lesões eram observadas no saco dorsal e saco cego caudo-dorsal do rúmen.
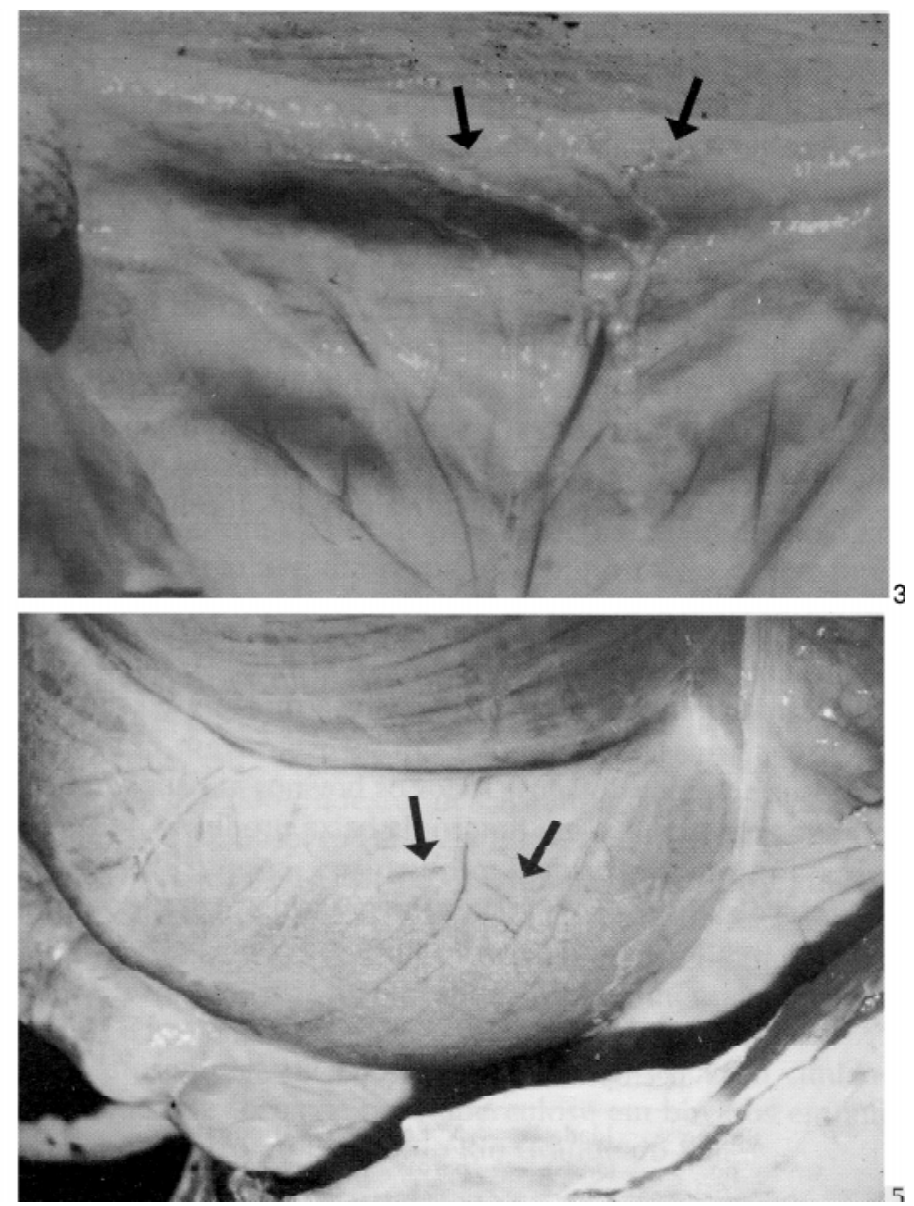

Fig. 3. Vasos linfáticos da serosa e do mesentério do intestino delgado dilatados e com aspecto varicoso (bovino 5).

Fig. 5. Mineralização da serosa do rúmen; lesões esbranquiçadas e granulares no saco dorsal (bovino 1).

O fígado estava diminuído de tamanho, escuro e com os bordos afilados. Em cinco animais (bovinos 1 a 4 e 7), havia atrofia do lobo caudado do fígado. Esta lesão consistia em uma faixa de tecido fibroso esbranquiçado que se continuava com o parênquima hepático. Em todos os casos, o baço estava aumentado de volume e pulposo. Ao corte, observavam-se folículos linfóides muito proeminentes.

\section{Achados histopatológicos}

As principais alterações microscópicas, presentes em todos os bovinos necropsiados, foram observadas no intestino delgado, nos vasos linfáticos do mesentério e nos linfonodos mesentéricos e incluíam enterite, linfangite e linfadenite granulomatosas. No intestino, a lesão foi observada principalmente na mucosa e submucosa do jejuno e íleo e caracterizava-se pela presença de infiltrado inflamatório formado por quantidade variável de linfócitos, plasmócitos e principalmente macrófagos que, com frequência, assumiram aspecto epitelióide ou células gigantes de Langhans. As células 


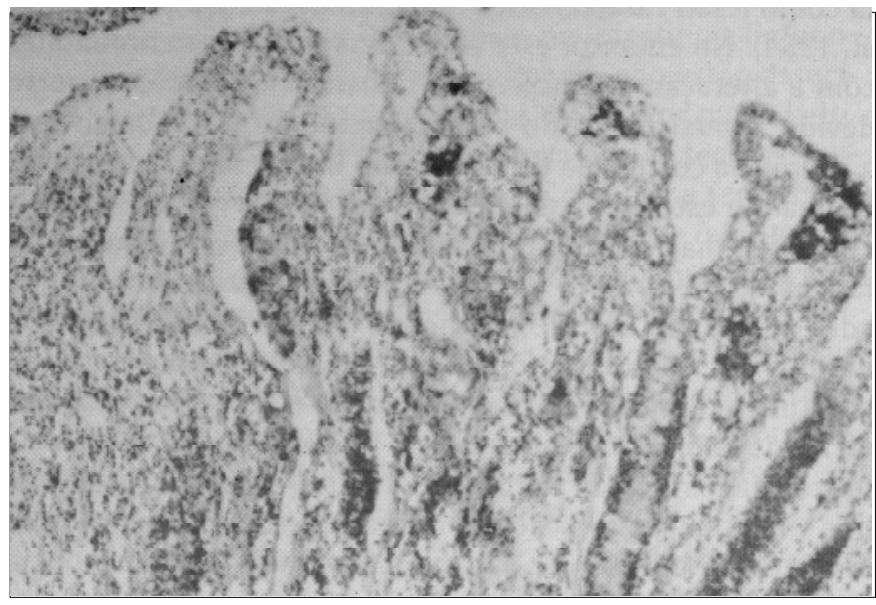

Fig. 6. Ileíte granulomatosa com aglomerados de macrófagos contendo bacilos álcool-ácido resistentes no ápice das vilosidades intestinais e dilatação do vasos linfáticos. Coloração de ZiehlNeelsen, obj. 4.

macrofágicas geralmente continham grande quantidade de bacilos álcool-ácido resistentes, positivos na técnica de ZiehlNeelsen, o que as tornava mais evidentes (Fig. 6). As células inflamatórias eram observadas, com mais frequência, na mucosa intestinal, predominantemente no ápice das vilosidades, onde se agrupavam, ou então distribuíam-se de forma difusa na lâmina própria. Havia dilatação dos vasos linfáticos das vilosidades intestinais. Muitas destas vilosidades estavam fundidas devido à presença de grande quantidade de células epitelióides na mucosa. Em dois animais (bovinos 5 e 6), a inflamação se estendia à porção ascendente do cólon proximal. Neste segmento do intestino grosso, macrófagos preenchidos por microrganismos álcool-ácido resistentes eram encontrados principalmente na submucosa.

Linfangite granulomatosa foi observada nos intestinos e mesentério (Fig.7). Na parede dos linfáticos e ao redor destes, havia infiltrado inflamatório formado por grande quantidade de linfócitos e plasmócitos e um número menor de macrófagos. Na luz destes vasos, havia grande quantidade de macrófagos e de células gigantes de Langhans, contendo bacilos Ziehl-Neelsen positivos (Fig. 8). Muitas destas células inflamatórias formavam aglomerados que se aderiam às válvulas e ao endotélio dos linfáticos provocando obstrução parcial ou total da luz. As células gigantes muitas vezes apresentavam citoplasma vacuolizado.

Nos linfonodos mesentéricos, a inflamação granulomatosa afetava as regiões cortical e medular e consistia em infiltrado composto por grande quantidade de macrófagos e de células gigantes de Langhans nos seios subcapsulares e medulares. Os centros germinativos apresentavam-se mais celulares e, em seus bordos, eram observados macrófagos preenchidos por pigmento amarelo-ouro e refringente, sob a forma de grânulos, positivo na coloração de perls para ferro (hemossiderina). Os linfonodos hepáticos apresentavam alterações inflamatórias semelhantes às dos mesentéricos, porém de

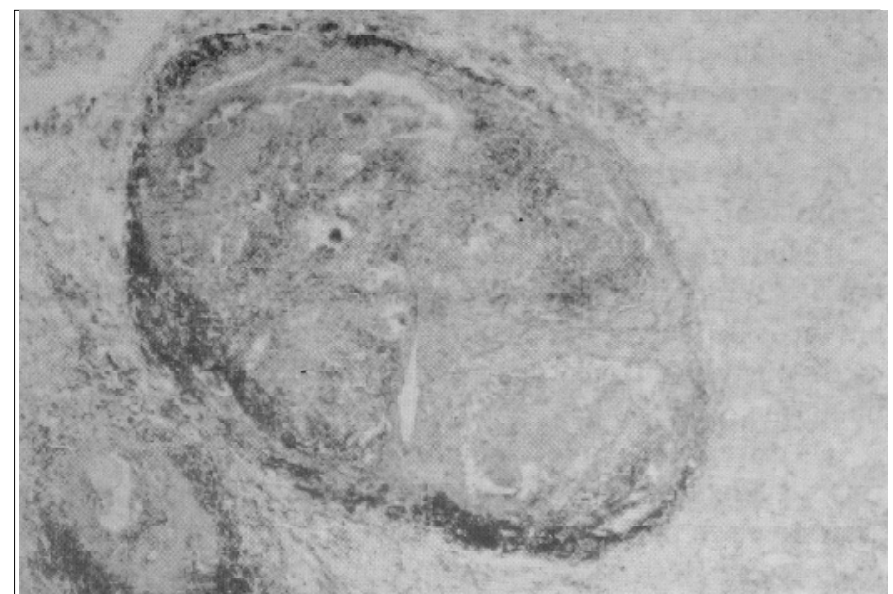

Fig. 7. Linfangite granulomatosa no mesentério. Obstrução de vaso linfático por numerosos macrófagos e aglomerados perivasculares formados por linfócitos e plasmócitos. Coloração de Ziehl-Neelsen, obj. 4.

menor intensidade. Nos linfonodos mesentéricos de um animal (bovino 1), havia pequenos focos de necrose caseosa, associados à inflamação granulomatosa. As lesões vasculares consistiam em degeneração e mineralização das túnicas íntima e média das artérias de grande calibre e fibroplasia.

No rúmen, áreas de calcificação intensamente basofílicas e discreta reação inflamatória macrofágica foram observadas na serosa. Por vezes, os macrófagos formavam células gigantes do tipo corpo estranho nos bordos dos focos de mineralização.

Hepatite granulomatosa multifocal foi observada em todos os bovinos e caracterizava-se pela presença de quantidade variável de microgranulomas formados por linfócitos, plasmócitos, macrófagos e células gigantes de Langhans. Em dois casos (bovinos 5 e 6), macrófagos contendo pequena quantidade de bacilos álcool-ácido resistentes estavam associados a este infiltrado inflamatório. Havia também atrofia

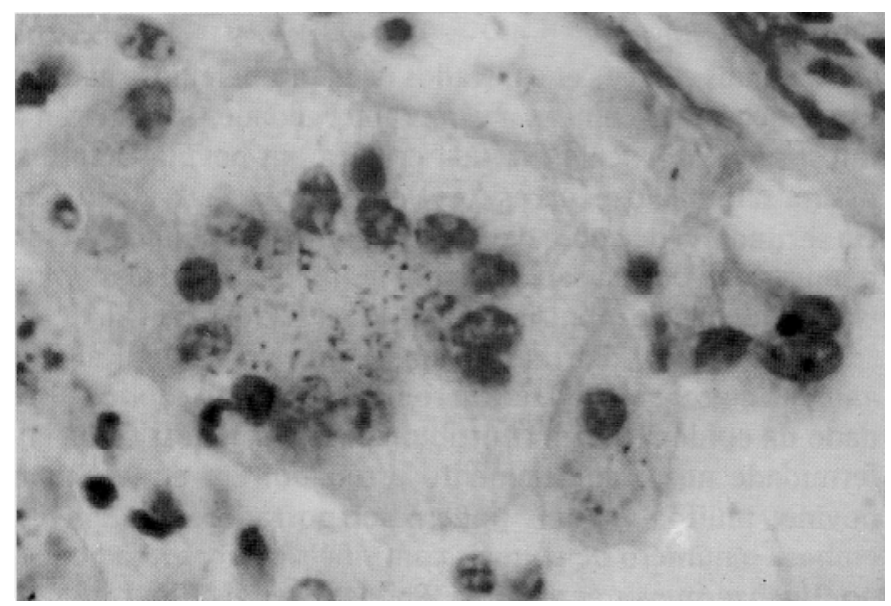

Fig. 8. Célula gigante de Langhans com bacilos álcool-ácido resistentes na parede de vaso linfático do mesentério. Coloração de ZiehlNeelsen, obj. 100. 
hepatocelular difusa que consistia em hepatócitos diminuídos de tamanho e achatados, de modo que a luz dos capilares sinusóides tornava-se mais evidente.

O baço apresentava hiperplasia folicular acentuada com centros foliculares reativos e hemossiderose perifolicular acentuada.

Lesões de pele na região perianal de dois bovinos (bovinos 1 e 3) incluíam dermatite necro-supurativa que consistia em focos de ulceração da epiderme acompanhada da presença de pústulas intracorneais e infiltrado linfoplasmocitário na derme.

Os esfregaços confeccionados a partir de raspados intestinais evidenciaram microrganimos positivos na técnica de Ziehl-Neelsen para bacilos álcool-ácido resistentes. $\mathrm{O}$ cultivo em meio de Herrold enriquecido com micobactina revelou o crescimento de colônias bacterianas, após um período superior a seis semanas. Não houve crescimento bacteriano nas amostras semeadas em meio de Herrold sem micobactina. Mycobacterium paratuberculosis foi cultivado dos raspados do intestino em todos os oito casos.

\section{DISCUSSÃO}

O diagnóstico de paratuberculose neste estudo foi baseado nos dados epidemiológicos, nos sinais clínicos, nos achados de necropsia, nas lesões histopatológicas e no isolamento do agente etiológico da enfermidade em meio de cultivo específico. Os sinais clínicos e alterações macro e microscópicas observados nestes casos são semelhantes aos descritos na infecção por Mycobacterium paratuberculosis em bovinos (Buergelt et al. 1978, Chiodini et al. 1984, Huchzermeyer et al. 1994, Radostits et al. 1994, Whittlock \& Buergelt 1996).

O sinal clínico de diarréia é descrito com frequência na paratuberculose em bovinos (Radostits et al. 1994, Whittlock \& Buergelt 1996). Diarréia crônica, intermitente, acompanhada de emagrecimento progressivo, foi observada em todos os casos deste estudo. A diarréia ocorre devido à má absorção de nutrientes, em função da enterite granulomatosa, o que justifica a perda progressiva de peso e o mau estado corporal dos animais afetados (Chiodini et al. 1984, Whittlock \& Buergelt 1996).

Os sinais clínicos encontrados na paratuberculose não são específicos, mas comuns a várias enfermidades que afetam o intestino e provocam diarréia crônica em bovinos adultos. Assim, salmonelose, parasitoses gastrointestinais e deficiência secundária de cobre devido ao excesso de molibdênio são doenças que devem ser consideradas no diagnóstico diferencial da doença de Johne (Stehman 1990, Radostits et al.1994).

Neste relato, diarréia foi observada apenas em alguns animais do rebanho e afetava somente bovinos adultos. Este dado da epidemiologia contribuiu para o diagnóstico da enfermidade no estabelecimento estudado. Em um rebanho bovino, muitos animais podem ser portadores do agente embora o número de animais com sinais clínicos seja pequeno (Huchzermeyer et al. 1994, Radostits et al. 1994).

Mucosa intestinal espessada, irregular, de aspecto reticulado e com dobras transversais bem evidentes é descri- ta como lesão característica da paratuberculose (Chiodini et al. 1984). No entanto, este achado não deve ser confundido com a alteração que ocorre no intestino logo após a morte devido à persistência do peristaltismo. Na paratuberculose, a aparência corrugada da mucosa do intestino não desaparece quando este é estirado (Stehman 1990).

Lesões macroscópicas no intestino delgado, nos vasos linfáticos do mesentério e nos linfonodos mesentéricos e que correspondiam histologicamente à enterite, linfangite e linfadenite granulomatosas, são usualmente descritas na paratuberculose em bovinos (Buergelt et al. 1978, Chiodini et al. 1984). Estas lesões foram observados nos animais necropsiados neste relato. No entanto, é importante frisar que nem sempre todas estas alterações estão presentes em um mesmo animal ou são pouco evidentes à necropsia (Chiodini et al. 1984).

Mineralização do endocárdio e da parede das artérias tem sido descrita na paratuberculose (Alibasoglu et al. 1962, Buergelt et al. 1978). Esta alteração foi observada em todos os bovinos necropsiados neste estudo, embora não seja descrita com frequência nesta enfermidade. A patogenia desta alteração vascular não está completamente esclarecida. Lesões vasculares observadas em várias doenças causadas por micobactérias, incluindo a paratuberculose, podem ser atribuídas à hipercalcemia associada a níveis elevados de vitamina $D_{3}$ (Stabel \& Golf 1996). Sugere-se que estes distúrbios metabólicos estejam associados às extensas lesões granulomatosas nos intestinos (Alibasoglu et al. 1962). As alterações vasculares e a patogenia sugerida para o desenvolvimento destas lesões são comparáveis àquelas descritas nas intoxicações por plantas calcinogênicas, cujos princípios ativos são semelhantes ao da vitamina $D_{3}$ (Döbereiner et al. 1971, Riet-Correa et al. 1987). Provavelmente o mesmo mecanismo patogenético seja responsável pela calcificação da serosa do rúmen.

Calcificação da íntima das artérias tem sido descrita em diversas doenças caquetizantes em bovinos tais como a paratuberculose e a tuberculose. Também é um achado de necropsia incidental em animais velhos (Kitt 1927, Robinson \& Maxie 1993). Trata-se, portanto, de uma lesão inespecífica.

Achados de necropsia menos específicos, tais como mau estado corporal das carcaças, atrofia serosa dos depósitos de gordura, edema das dobras do abomaso e atrofia do lobo caudado do figado foram observados nos casos deste relato. Estes achados podem ser atribuídos aos distúrbios na absorção intestinal que resulta em diversas deficiências nutricionais, inclusive hipoproteinemia. Edema intermandibu-lar associado à hipoproteinemia tem sido descrito na paratu-berculose (Dacorso Filho et al. 1960, Whitlock \& Buergelt 1996) porém, não foi observado no presente estudo.

Os dados da epidemiologia e o quadro clínico-patológico da paratuberculose em bovinos precisam ser diferenciados dos da tuberculose. No rebanho estudado, todos os animais que reagiram positivamente à tuberculinização com tuberculina mamífera e foram enviados para abate, apresentaram lesões de tuberculose. No entanto, nenhum dos animais necropsiados com paratuberculose reagiu à prova cau- 
dal simples com tuberculina mamífera. Na paratuberculose em bovinos, as lesões granulomatosas no intestino e linfonodos mesentéricos são difusas e geralmente não estão associadas à necrose caseosa (Buergelt et al. 1978). Por outro lado, na tuberculose, a reação granulomatosa nestes tecidos usualmente está acompanhada de necrose caseosa e tem distribuição focal (Kitt 1927). É importante salientar que pequenos focos de necrose caseosa em linfonodos mesentéricos são ocasionalmente observados na paratuberculose de bovinos e restringem-se àqueles casos de evolução clínica mais prolongada (Kreeger 1991). Outros achados que caracterizam a paratuberculose incluem a ausência de lesões nos linfonodos retrofaríngeos e mediastínicos. $\mathrm{O}$ isolamento do agente em meio de cultivo específico também confirmou a etiologia da doença neste estudo.

\section{REFERÊNCIAS}

Alibasoglu M., Dunne H.W. \& Guss S.B. 1962. Naturally occurring arteriosclerosis in cattle infected with Johne's disease. Am. J. Vet. Res. 23:49-57.

Buergelt C.D., Hall C., McEntee K. \& Duncan J.R. 1978. Pathological evaluation of paratuberculosis in naturally infected cattle. Vet. Pathol. 15:196-207.

Chiodini R.J. \& Rossiter C.A. 1996. Paratuberculosis: a potential zoonosis? In: Sweeney R.W. (ed.) Paratuberculosis (Johne's disease). Vet. Clin. North Am. 12(2):457-467.

Chiodini R.J., Van Kruiningen H.J. \& Merkal R.S. 1984. Ruminant paratuberculosis (Johne's disease): the current status and future prospects. Cornell Vet. 74:218-262.

Collins M.T. 1996. Diagnosis of paratuberculosis. In: Sweeney R.W. (ed.) Paratuberculosis (Johne's disease). Vet. Clin. North Am. 12(2):357-371.

Dacorso Filho P., Campos I.O.N., Faria J.F. \& Langenegger J. 1960. Doença de Johne (paratuberculose) em bovinos nacionais. Arqs Inst. Biol. Animal, Rio de J., 3:129-139.

Döbereiner J., Tokarnia C.H., Costa J.B.D., Campos J.L.E. \& Dayrell M.S. 1971. "Espichamento", intoxicação de bovinos por Solanum malacoxylon, no Pantanal de Mato Grosso. Pesq. Agropec. Bras. 6:91-117.

Huchzermeyer H.F.A.K, Brückner G.K. \& Bastianello S.S. 1994. Paratuberculosis. In: Coetzer J.A.W., Thomson G.R. \& Tustin R.C.(ed.) Infectious Diseases of Livestock with Special Reference to Southern Africa. Vol. 2. Oxford University Press, Cape Town, p. 1445-1457.

Hutchinson L.J. Economic impact of paratuberculosis. In: Sweeney R.W. (ed.) Paratuberculosis (Johne's disease). Vet. Clin. North Am. 12(2):373-381.

Kitt T. 1927. Lehrbuch der Pathologischen Anatomie der Haustiere. Vol. 3. 5. Aufl. Ferdinand Enke, Stuttgart. 695p.
Kreeger J.M. 1991. Ruminant paratuberculosis - a century of progress and frustration. J. Vet Diagn. Invest. 3:373-383.

Merkal R.S., Whipple D.L., Sacks J.M. \& Snyder G.R. 1987. Prevalence of Mycobacterium paratuberculosis in ileocecal lymph nodes of cattle culled in the United States. J. Am. Vet. Med. Assoc. 190:676-680.

Nakajima M., Maia F.C.L. \& Mota P.M.P.C. 1991. Diagnóstico da paratuberculose em Minas Gerais. IV Simpósio Brasileiro em Micobactérias, Bauru, SP, 4 a 8 novembro. (Abstract)

Poester F.P. \& Ramos E.T. 1994. Infecção experimental em caprinos com Mycobacterium pararuberculosis de origem bovina. Ciência Rural, Santa Maria, 24(2):333-337.

Portugal M.A.S.C., Pimentel J.N., Saliba A.M., Baldassi L. \& Sandoval E.F.D. 1979. Ocorrência de paratuberculose no estado de Santa Catarina. Biológico, São Paulo, 45(1/2):19-24.

Radostits O.M., Blood D.C. \& Gay C.C. 1994. Veterinary Medicine. 8th ed. Baillière Tindall, London. 1763p.

Ramos, E.T., Poester F.P., Correa B.L., Oliveira S.J., Rodrigues N.C. \& Canabarro C.E. 1986. Paratuberculose em bovinos no Estado do Rio Grande do Sul. Hora Vet., Porto Alegre, 6(34):28-32.

Riet-Correa F., Schild A. L., Méndez M.C., Wasserman R \& Kook L 1987 Enzootic calcinosis in sheep caused by the ingestion of Nierembergia veitchii (Solanaceae). Pesq. Vet. Bras. 7(3):85-95.

Robinson W.F. \& Maxie M.G. 1993. The cardiovascular system, p. 1-100. In: Jubb K.V.F., Kennedy P.C. \& Palmer N. (ed.) Pathology of Domestic Animals. Vol. 3. 4th ed. Academic Press, San Diego.

Santos J.A. \& Silva N.L. 1956. Sobre a $1^{\text {a }}$ observação da paratuberculose no Brasil. Bolm Soc. Bras. Med. Vet. 24:5-11.

Silva N.M. \& Pizelli G.N. 1961. Estudos sobre a paratuberculose. I. Diagnóstico de um caso da doença. Arqs Inst. Biol. Animal, Rio de J., 4:169-173.

Stabel J.R. \& Golf J.P. 1996. Influence of vitamin $D_{3}$ infusion and dietary calcium on secretion of interleukin 1, interleukin 6, and tumor necrosis factor in mice infected with Mycobacterium paratuberculosis. Am. J. Vet. Res. 57:825829.

Stabel J.R. 1997. An improved method for cultivation of Mycobacterium paratuberculosis from bovine fecal samples and comparison to three other methods. J. Vet. Diagn. Invest. 9:375-380.

Stehman S.M. 1990. Moléstia de Johne (Paratuberculose), p. 823-829. In: Smith B.P. (ed.) Tratado de Medicina Interna de Grandes Animais. Vol. 1. Manole, São Paulo.

Sweeney R.W. 1996. Transmission of paratuberculosis. In: Sweeney R.W. (ed.) Paratuberculosis (Johne's disease). Vet. Clin. North Am. 12(2): 305-312.

Whitlock R. H. \& Buergelt C. 1996. Preclinical and clinical manifestations of paratuberculosis (including pathology). In: Sweeney R.W. (ed.) Paratuberculosis (Johne's disease). Vet. Clin. North Am. 12(2):345-356. 